\title{
FATAL ACUTE IODISM AFTER BRONCHOGRAPHY
}

\author{
BY
}

\author{
JOHN SUMNER, A. I. LICHTER, AND E. NASSAU \\ From Harefield Hospital, Middlesex
}

Since the introduction of iodized oil for routine bronchography in 1922 there have been several reports of untoward reactions following the procedure, and a few were fatal. This is a report of another fatality from what is now considered to be a minor investigation.

\section{CASE REPORT}

A woman, aged 40 years, was admitted for investigation of an illness of two months duration, characterized by left-sided pleuritic pain, dyspnoea, and cough with sputum which was blood-stained on one occasion. There was associated myxoedema which had been treated with a thyroid gland preparation for six years, and also a refractory anaemia of two years' duration.

On admission the patient's only symptom was dyspnoea. She was an obese woman with a slightly lemon-coloured skin, and minimal clubbing of the fingers. There was dullness and diminished air entry at the base of the left lung. On radioscopy the diaphragm was mobile. Radiography showed atelectasis and consolidation at the base of the left lung. Bronchoscopy showed a dilatable stenosis of the left main stem bronchus.

At this stage it was considered that the probable diagnosis was that of bronchogenic carcinoma of the left lower lobe, although bronchoscopy had proved inconclusive. it was decided that a bronchogram should be done in an attempt to confirm the diagnosis.

At 11 a.m. on February 8, 1950, a left-sided bronchogram was carried out by injecting $14 \mathrm{ml}$. of iodized oil through the crico-thyroid membrane. This showed a normal bronchial tree.

On the afternoon of the first day, four hours after bronchography, the patient developed a severe coryza and lacrimation with dyspnoea, difficulty in talking, and increased cough and sputum. On the second day small, red-brown macules appeared first on the forearms and, on the third and fourth days, on the face, nose, tongue, and under the chin. Within 24 to 48 hours the macules had become papular, then vesicular, and finally pustular. The vesicles and the pustules were umbilicated. The pustules on direct examination and culture contained a penicillin-sensitive strain of Staph. aureus. The skin reaction was associated with a pyrexia ranging from $99.2^{\circ}$ to $101^{\circ} \mathrm{F}$.. and the signs of acute bronchitis, laryngitis, and pharyngitis. Radiography on the second day after bronchography showed the presence of opaque oil in the left lower lobe, but not in the stomach.

On the fourth day a severe purulent conjunctivitis developed. At this time the tongue became oedematous and shortly afterwards pustules similar to those upon the skin appeared on it. On the sixth day the pustules upon the face, nose, and forearms began to coalesce and to break down, leaving large red, granulomatous areas, particularly on the extensor surfaces of the forearms. The nose, especially in the region of the ala nasae, was covered in pustules which burst and discharged leaving a slowly progressive erosion of the nares. The patient was seriously ill with an intermittent fever up to $102^{\circ} \mathrm{F}$. and the pulse rate ranged between 130 and 140 . The white blood 


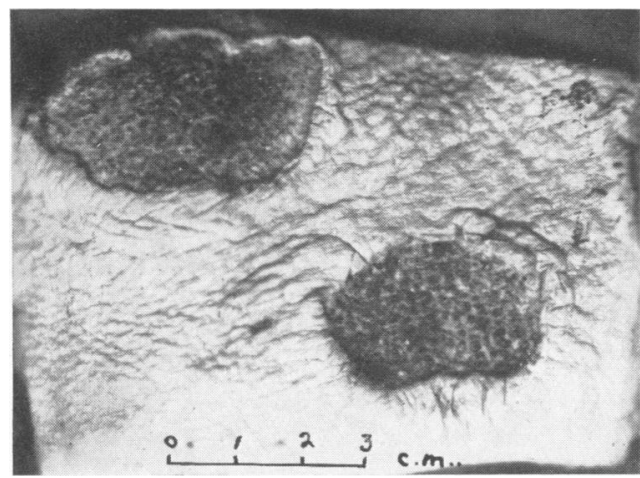

FIG. 1a.-The post-mortem appearance of the skin ulcers on the forearm.

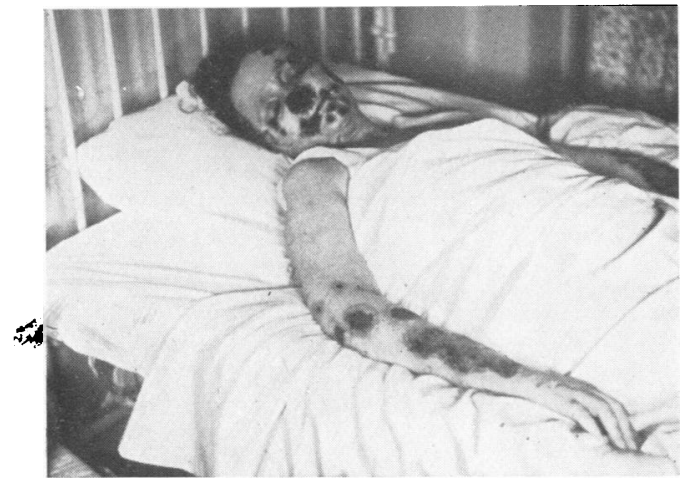

FIG. 1b.-The post-mortem appearance of the ulceration of the skin of the face and of the forearm.

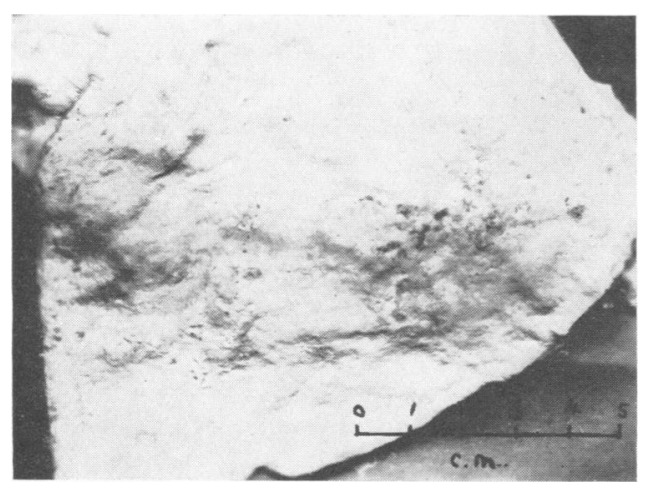

FIG. 2.-The post-mortem appearances of the ulceration of the stomach. cell count rose from 9,000 to 32,500 per

c.mm. Iodine was present in the urine. There were scattered crepitations throughout both lungs, and quantities of purulent sputum were coughed up. Laryngeal obstruction by oedema and thick sputum was sufficient to indicate preparation for tracheotomy. The patient's general condition rapidly deteriorated, and two weeks after the bronchogram was performed she died.

The picture was that of acute iodism rapidly progressing to death. The condition was recognized when the first symptoms appeared, and evacuation of the residual oil from the bronchial tree by forced postural coughing was begun and continued until the patient became too ill to co-operate.

The treatment adopted was as follows: eight days before the bronchogram a course of penicillin, 1 million units twice daily, had been prescribed, and this was continued after the bronchography. Sodium chloride, 30 gr. $(1.0$ g.) thrice daily by mouth, was prescribed on the third day, together with " benadryl" (25 mg. thrice daily). Sodium thiosulphate solution was given in doses of $10 \mathrm{ml}$. of a $10 \%$ solution intravenously at intervals of three days for a total of four injections. Local saline dressings were applied to the arms, and saline drops instilled in the eyes. This treatment did not influence the progress of the lesions in any way. In the later stages of the condition preparations for tracheotomy for laryngeal obstruction were made but proved unnecessary.

Post-mortem examination performed 14 hours after death showed that on the face, extensor aspects of the forearms and hands, and scantily on the upper parts of the chest, there were skin lesions in varying stages: (1) raised opaque vesicles varying in diameter from $\frac{1}{4}$ to 1 in. (6 to $25 \mathrm{~mm}$.) containing watery fluid ; (2) the same lesions after rupture leaving a heaped-up edge with granulating central area (Fig. 1a); (3) the lesions coalescing and covering a large area on both forearms; (4) a more advanced stage 
involving the mucous membrane of the nose and lips with ulceration and destruction (Fig. 1b).

There were similar lesions on the tongue and the laryngeal mucosa with ulceration of the vocal cords. The air passages contained necrotic debris and there was necrosis of the epithelium of the trachea and bronchi extending down into the small bronchioli. Thick pus was present in both lower lobes, with patchy consolidation on the left side. The stomach showed areas of ulceration near the pyloric end which were similar in character to the skin lesions (Fig. 2). The spleen was enlarged to twice its normal size ; the central portion was soft, but the remainder had undergone complete liquefaction. The kidney and the bone marrow showed no abnormality macroscopically.

Death was due to bronchopneumonia following ulcerative laryngitis and bronchitis, which were the result of acute iodism.

\section{Histology}

Lungs.-The main bronchi and their principal divisions showed necrosis and ulceration of the mucosa. The submucosa was infiltrated by polymorphs and contained many congested capillaries. There was necrosis of some of the bronchial glands. In the wall of the main bronchi there were some arteries showing fibrinoid necrosis of their walls (Fig. 3). There was thrombosis of some capillaries. Eosinophils were not conspicuous. The peripheral part of the lung showed severe congestion and oedema. The small bronchi were distended with pus. Scattered bronchopneumonic areas were seen.

Stomach.-The ulcers had raised edges, and their bases were formed of granulation tissue containing numbers of thrombosed capillaries. There was fibrinoid necrosis of the walls of some small arteries (Fig. 4).

Skin.-The ulcers on the skin showed a similar picture to those found in the stomach (Fig. 5).

The kidneys were not examined histologically.

The necrotic changes seen in the bronchial tree, gastric mucosa, and skin were accompanied by vascular changes of the small arteries which, in some respects, resembled the changes seen in polyarteritis nodosa.

\section{Discussion}

Incidence.-Twelve reports of severe reactions to iodized oil have been traced, and of these cases four were fatal (O'Donovan, 1927 ; Scadding, 1934 ; Goldstein, 1936 ; and Mahon, 1946). With the exception of those of Kooperstein and Bass (1946) and Mahon, who describe pulmonary changes and acute asthma respectively, the descriptions closely resemble this case and the classical description of acute iodism of Parkes Weber (1923) and many writers on iodism from 1879 onwards (Fox, Bumstead, and Taylor, quoted by Hyde, 1886).

Scadding (1934) stated that of 2,900 iodized oil examinations performed at the Brompton Hospital, London, only two had been associated with severe iodine reactions. Of these two cases one was terminated by death in similar circumstances to our case. The same writer reported two main groups of less severe reactions ; (1) frequent transient reactions of a minor nature lasting a few days characterized by coryza, lacrimation, urticaria, and an erythematous skin rash, and (2) a few rather more severe skin changes appearing from seven to ten days after bronchography. White and Bayliss (1943), on the other hand, stated that their colleague who had performed 2,000 bronchograms in a Sydney hospital reported no ill effects. 
Fig. 3.-The histological appearances of the lesions in the bronchus: a small thrombosed artery showing fibrinoid necrosis of the wall. Haematoxylin and eosin. $\times 350$.

Fig. 4.-The histological appearance of the lesions in the stomach. Weigert's stain for elastic tissue shows gap in elastica. $\times 350$.

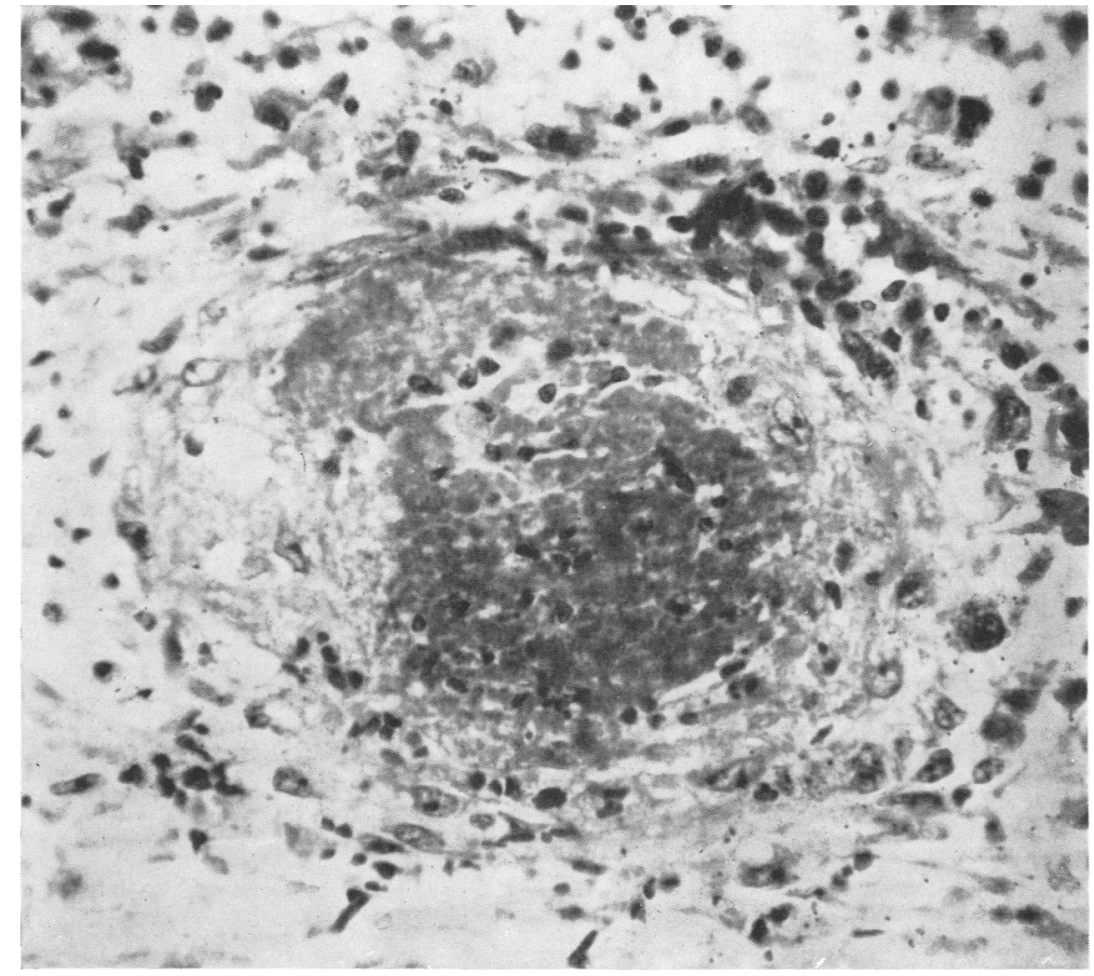

FIG. 3.

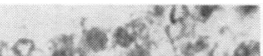

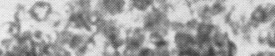

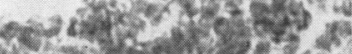
2.

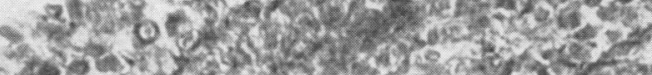

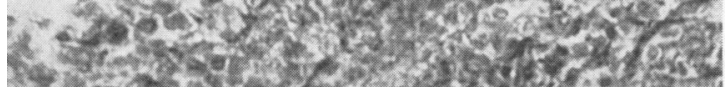

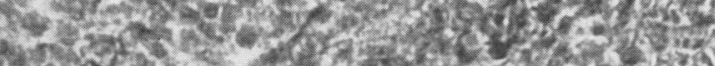

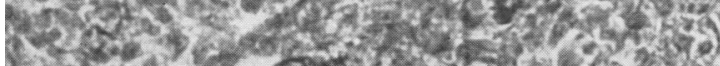

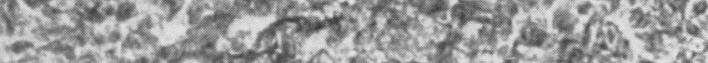

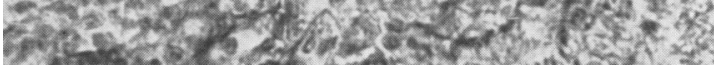

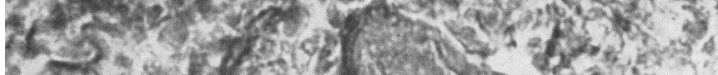
5.5.

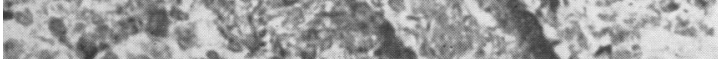

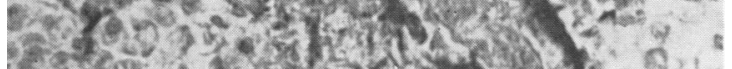
ks

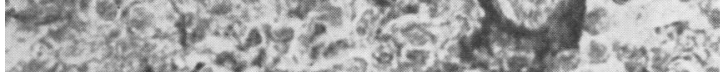
G.6.

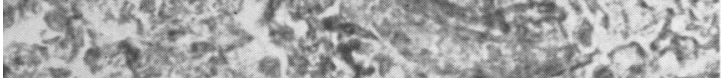

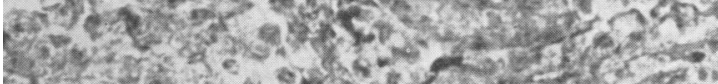

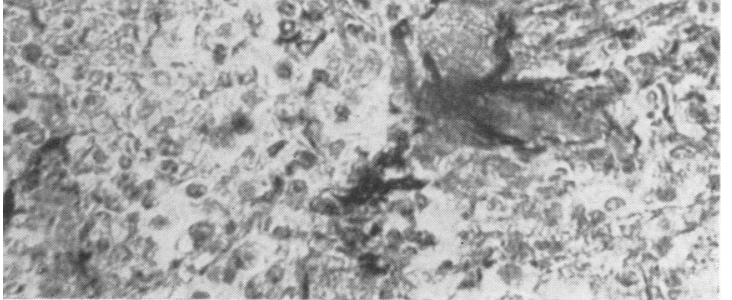

FIG. 4.

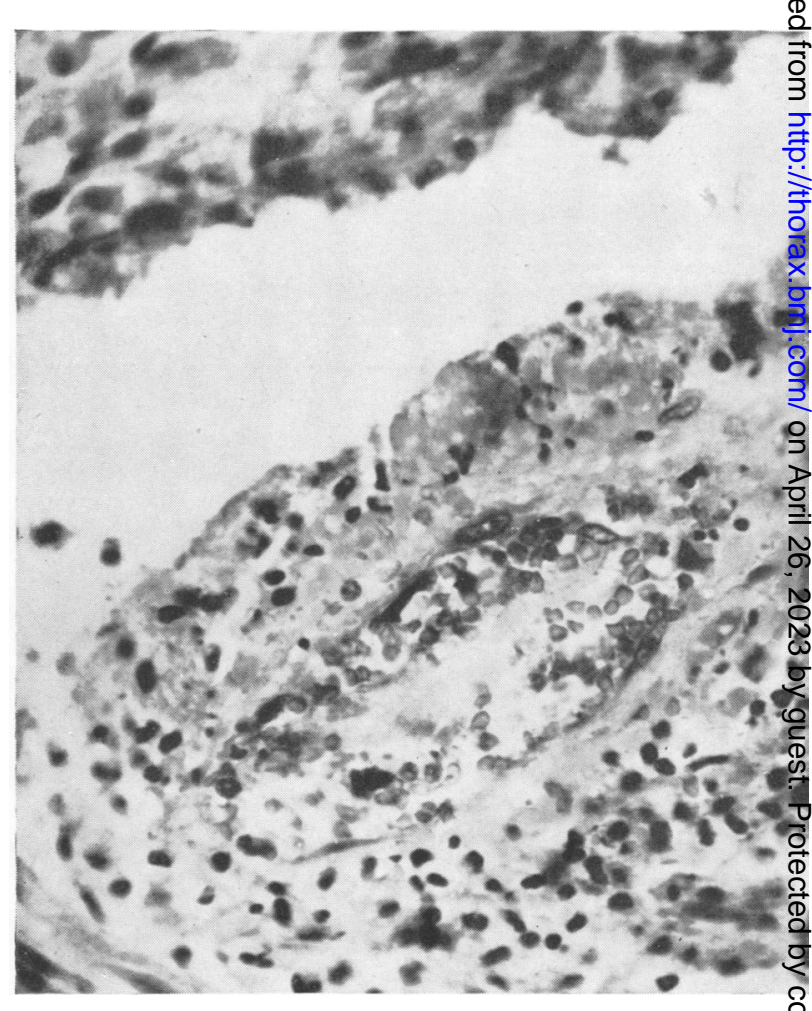

FIG. 5.-The histological appearance of the lesions in the showing fibrinoid necrosis of the blood vessel wall. Haematoxylin and eosin. $\times 350$. 
The records of 2,279 bronchograms performed at Harefield Hospital from 1941 until 1949 have been searched. This is the first instance of a severe iodine reaction followed by death at this hospital. In one other case the bronchogram was followed by pneumonitis due to the iodized oil ; this appeared to be similar to the three cases of pulmonary changes described by Kooperstein and Bass (1946). We have failed to find any other reports of severe iodine reactions. It is possible that more cases may have occurred without being reported, especially since one of the manufacturers of iodized oil has indicated that other cases have been brought to his notice without subsequently appearing in the literature (Day, 1950).

Description of Reactions to lodized Oil.-The possible dermal and mucosal manifestations of iodism as described in the literature may be summarized as follows: urticaria, which may be general or localized to the face ; erythematous rash ; maculo-papular rash ; pustular acneiform rash ; vesicular or bullous rash ; fungating (mycotic) papillomatous rash.

The character of the rash may progress from the first type to the last, or may be arrested at any stage. The size and extent of the lesions are variable; they are usually of a reddish brown colour, and may be haemorrhagic. They are most commonly reported upon the face, the neck, the chest, and the extensor surfaces of the forearms, the hands, and the thighs. Similar lesions may appear on the mucous membrane of the nose, the mouth, the pharynx, larynx, trachea, and bronchi, the oesophagus, and the stomach. No lesions have been reported in the small intestine.

Oedema of the skin and mucous membranes may be extreme and is common. Oedema of the larynx may necessitate tracheotomy.

Conjunctivitis is common. It may be simple, producing lacrimation as the only symptom, or may progress to an acute purulent condition.

Painful swelling of the salivary glands may result from the mucosal changes and may be complicated by acute inflammation.

The general manifestations are important. The febrile response is immediate, dramatic, and sustained. Pain at the site of both the rash and the mucosal lesions is severe and constant. Dysphonia, dyspnoea, and dysphagia are early symptoms. Coryza, lacrimation, and excess of salivation occur with the mucosal changes. Painful swelling of the thyroid gland occurs. Bronchitis is common and may progress to bronchopneumonia, which is the commonest immediate cause of death.

Nephritis is also common, and is the second most important immediate cause of death.

Prognosis.- The changes due to iodism may occur shortly after the administration of iodized oil or may be delayed. The manifestations may appear within four hours (Shapiro, 1946) or as long as 17 days after the administration (Robinson, 1938). Recovery can occur at any stage ; at the fourteenth day as reported by White and Bayliss (1943), or as late as three months (Carmichael, 1932, and Firth, 1933). Death may occur from 54 hours (Scadding, 1934) to 40 days (O'Donovan, 1927) after the bronchogram.

From our perusal of the literature there appears to be no difference between those cases showing an early reaction to iodine and those showing a late reaction: it would appear impossible to state in which type of case the outcome may be serious. We 
feel, however, that in general an optimistic prognosis is indicated. Certainly there appears to be no reason for discontinuing the use of iodized oil because of the remote possibility of serious complications. In this we agree with White and Bayliss (1943).

Treatment.-There is no doubt that severe reactions to iodized oil for bronchography are due to the iodine and not to the poppy seed oil base. The lesions resemble in all respects those due to the administration of iodides in the treatment of syphilis described by many since 1886 . It is certain that iodine can enter the circulation as readily through the bronchial mucosa as through the intestinal mucosa (Sicard and Forestier, 1922). Hyde, Van Nuys, and Hyde (1949) investigated blood iodine levels after bronchography in 30 subjects, and showed increases from the normal of $4-8 \mu \mathrm{g}$. per $100 \mathrm{ml}$. to $400 \mu \mathrm{g}$. per $100 \mathrm{ml}$. one week after bronchography. The iodine blood levels did not fall to the normal range until 17 months after the instillation, demonstrating continued absorption from the lungs and a slow rate of excretion.

The urgent indications for treatment, therefore, are (1) the removal of the reservoir of iodine from the bronchi and from the stomach by posturing and forced coughing and by the aspiration of the residue; and (2) the attachment of the free iodine to a sodium ion to facilitate renal excretion by the administration of sodium chloride. The doses recommended are $20 \mathrm{gr}$. $(0.7 \mathrm{~g}$. $)$ of sodium chloride in capsules four-hourly by mouth, together with $100-400 \mathrm{ml}$. of $0.9 \%$ sodium chloride solution intravenously every three days. Scadding (1934) suggests $25 \mathrm{oz}$. (700 ml.) $1.8 \%$ sodium chloride solution intravenously. Sodium may also be given as sodium thiosulphate, $10 \mathrm{ml}$. of a $10 \%$ solution intravenously. Chemotherapy is necessary to control secondary infection of the skin or mucosal lesions. Antihistamine drugs are given on the principle that this is an allergic type of reaction, but they appear to have little value.

Recently Selye (1950) has stated that conditions due to drug sensitization may be susceptible to treatment by adrenocorticotropic hormone or by cortisone.

Sensitivity Tests.-The commonest test for sensitivity to iodine before bronchography has been the administration of potassium iodide by mouth. No one appears satisfied with it: iodism from iodized oil can occur after a negative potassium iodide sensitivity test (Robinson, 1938). Kooperstein and Bass (1946) have suggested that a cutaneous scratch test using iodized oil is more efficacious. Scadding (1934) has said that sensitivity tests will not exclude these rare complications, while Robinson (1938) stated that "it is unfortunate that there is no method of deciding iodine idiosyncrasy before bronchography." Both Scadding (1934) and White and Bayliss (1943) point out that their patients had had a previous bronchogram without ill effect, and the latter state further that their patient showed no reaction to several iodine skin tests after recovery from acute iodism. Eller and Fox (1931) reported a case of fatal iodism following the administration of potassium iodide to a patient who had been accustomed to use iodized salt as a condiment for years.

It is difficult to account for these variations. One would expect that a patient sensitive to iodine would react to it in whatever form it was introduced, and at any time. Are there other factors deciding the onset and degree of the iodine sensitivity reaction? Sensitization to iodine is believed to take place when iodine combines with 
a protein (Rich, 1945). Thus anaphylactic sensitization is possible, with all its consequences. The vascular changes found in our case are in fact the expression of such anaphylactic sensitization and closely resemble those found in polyarteritis nodosa. Similar vascular changes were demonstrated by Rich in a fatal case of iodism due to the administration of Lugol's solution to a patient with hyperthyroidism, and were regarded by him as polyarteritis nodosa.

\section{SUMMARY}

Severe iodism following bronchography is uncommon, but of 12 reported instances four have been fatal. Another fatal case is described together with the pathological and histological findings.

The histological findings were those of polyarteritis nodosa.

At an early stage of a reaction it is impossible to distinguish between minor and potentially fatal reactions. Sensitivity tests are not reliable.

Bronchography is an important method of investigating the bronchial tree, and, as severe reactions to iodine are rare, there is no reason for abandoning the procedure.

We wish to thank Dr. W. Pagel, pathologist, Central Middlesex Hospital, and Mrs. Cuthbert for their assistance with the histological preparations and the photomicrographs; Dr. F. J. V. Jenner, consultant dermatologist to West Middlesex and Hillingdon Hospitals, for his advice on the treatment of the skin lesions. Mr. T. Holmes Sellors, consultant thoracic surgeon, under whose care the patient was admitted, kindly gave us permission to publish.

\section{REFERENCES}

Carmichael, D. A. (1932). Canad. med. Ass. J., 26, 319.

Day, C. R. (1950). Personal communication.

Eller, J. J., and Fox, E. C. (1931). Arch. Derm. Syph., Chicago, 24, 745.

Firth, J. O. (1933). J. Amer. med. Ass., 100, 110.

Fox, T., Bumstead, A., and Taylor, R. W. Quoted by Hyde, J. N., J. cutan. Dis. (1886), 4, 353.

Goldstein, D. W. (1936). J. Amer. med. Ass., 106, 1659.

Hyde, L., Van Nuys, J., and Hyde, B. (1949). J. Lab. clin. Med., 34, 1516.

Kooperstein, S. I., and Bass, H. E. (1946). Amer. J. Roentgenol., 56, 569.

Mahon, G. S. (1946). J. Amer. med. Ass., 130, 194.

O'Donovan, W. J. (1927). Brit. med. J., 2, 935.

Rich, A. R. (1945). Bull. Johns Hopk. Hosp., $77,43$.

Robinson, S. S. (1938). Calif. west. Med., 48, 34.

Scadding, J. G. (1934). Brit. med. J., 2, 1147.

Selye, H. (1950). Ibid., 1, 1383.

Shapiro, L. (1946). J. Canad. med. Serv., 3, 163.

Sicard, J. A., and Forestier, J. (1922). Bull. Soc. méd. Hôp. Paris., 46, 463.

Weber, F. Parkes (1923). Brit. J. Derm. Syph., 35, 169.

White, B., and Bayliss, C. G. (1943). Med. J. Aust., 2, 421. 